\title{
BAR VERSUS LOCATOR ATTACHMENTS FOR MAXILLARY IMPLANT OVERDENTURES OPPOSED BY IMPLANT SUPPORTED MANDIBULAR OVERDENTURES. CLINICAL AND RADIOGRAPHIC EVALUATION
}

\author{
Ahmad Fathalla Shawky* and Ahmed Samir Ahmed Khair Allah**
}

\begin{abstract}
Purpose: The aim of this short-term clinical trial was to evaluate clinical and radiographic outcomes of Bar and Locator attachments used to retain maxillary implant overdentures opposed by implant supported mandibular overdentures.

Material and methods: Ten patients wearing conventional maxillary denture and implant supported mandibular overdentures received 4 implants in the maxillary arch using 2 stage surgical approach. Six months later maxillary overdentures were connected to the implants with locator (group 1) or bar (group 2) attachments. Plaque index, bleeding index, probing depth, implant stability, and marginal bone loss (using Cone beam computerized tomography) were evaluated at time of overdenture delivery, 6 months and 12 months later.
\end{abstract}

Results: Plaque and gingival indices increased significantly with time in bar group only. Bar overdentures recorded significant higher plaque and gingival scores than locator overdentures. No significant difference in pocket depth and implant stability was noted between time intervals or groups. Total marginal bone loss for locator group was significantly higher than bar group after 6 and 12 months. For both groups, marginal bone loss around canine implants was significantly higher than bone loss around premolar implants

Conclusion: Within the limits of this study, it could be concluded that both locator and bar retained maxillary overdentures are successful treatment options for patients complaining from instability of maxillary dentures opposed by implant retained mandibular denture. However, locator attachments are advantageous in terms of peri-implant soft tissue health and bar attachments are advantageous regarding peri-implant alveolar bone preservation.

KEY WORDS: Locator, bar, implant, overdenture, clinical, radiographic

* Associate Professor of Removable Prosthodontics, Faculty of Dentistry Beni- Suef University

** Associate Professor of Removable Prosthodontics, Faculty of Dentistry Mansoura University 


\section{INTRODUCTION}

Edentulous patients with maxillary complete denture and mandibular implant supported overdentures often subjected to degeneration changes in the maxillary edentulous arch similar to that observed with the traditional combination syndrome when maxillary conventional dentures are opposed by natural teeth in the anterior mandibular region ${ }^{1}$. These changes include ill fitted maxillary denture, heavy anterior occlusal pressure, maxillary bone resorption and flappiness ${ }^{2,3}$, fibrous downward growth of maxillary tuberosities, palatal mucosal proliferation, epulis fissuratum, bone resorption in posterior mandible and occlusal discrepancies ${ }^{1,4-6}$. Prevention of anterior occlusal pressure, and support and stabilization of the maxillary dentures with implants are mandatory in elimination of these atrophic changes ${ }^{7}$.

Implant supported maxillary overdentures are effective treatment options for patients complaining from in sufficient retention and stability of conventional maxillary dentures ${ }^{8}$. Such overdentures provide proper phonetics, adequate restoration of alveolar bone loss and lip support, good aesthetics and hygiene access that is not possible with a fixed maxillary prosthesis ${ }^{9}$. Compared to mandibular implant overdentures, maxillary implant overdentures often compromised by the reduced bone quality and volume, increased biomechanical forces resulted from labial and buccal implant angulation due to inclination of alveolar bone of premaxilla ${ }^{10,11}$, and increased crown height space that increase vertical cantilevers and moment loads ${ }^{12,13}$.

The number, position, parallelism of the implants as well as selection of attachment type potentially affect the success rate of maxillary implants supporting overdentures ${ }^{8,10}$. Several attachments can be used to retain overdentures to the implants such as splinted (bar/clip) or non-splinted (stud and magnetic) attachments ${ }^{8}$. Bar attachments distribute load between the implants, can be used with divergent implants ${ }^{14}$, had reduced rate of prosthetic complications ${ }^{15}$ and provide horizontal stability when the ridge is resorbed ${ }^{16}$. The Locator attachment is a selfaligning, have internal and external flange retention with different values of retention (colour coded), ${ }^{17}$ provide increased retention and stability ${ }^{18}$, and can be used with decreased interarch space to reduce denture base fracture thanks to their low profile ${ }^{19}$. Locators also can be used with angulated individual implants up to $40^{\circ}{ }^{20}$ without problems and can be easily replaced when retention is $\operatorname{lost}^{21}$.

Reviewing the literature, the evaluation of maxillary implants overdentures with different types of attachments opposed by mandibular implant supported overdentures are relatively scarce ${ }^{22,23}$ and not evaluate the effect of opposing dentition on implant survival rate. Therefore, the aim of this study was to evaluate clinical and radiographic tissue health around bar and Locator attachments for maxillary implant overdentures opposed by implant supported mandibular overdentures. The null hypothesis was that there will be no significant difference in these outcomes between both attachments

\section{MATERIALS AND METHODS}

Ten participants $(5$ males and 5 females, age ranged from 55 to 65 years) wearing a maxillary traditional conventional denture opposing with mandibular ball retained implant overdentures who participated in a previous study3 were selected for the current study (fig 1). The participants regularly attended at the clinic of Prosthodontic Department for follow up, managing of prosthetic complications, adjustment of the retention of ball attachments and adjustment of occlusion. The selected participants had the following inclusion criteria: 1) All patients were complaining about the retention and stability of maxillary conventional denture and showed clear preference for an implant supported restoration. 2) All patients had sufficient residual alveolar bone height and width (quantity) and quality anterior to maxillary sinus of the maxilla, this was verified by a diagnostic preoperative cone beam computerized tomography. 3) All patients had sufficient restorative space of at least $15 \mathrm{~mm}$ from the mucosa covering the crest of the maxillary residual 
ridge to proposed occlusal plane to allow construction of bar attachments. Tentative jaw relation was used to detect the restorative space. The protocol of the study was reviewed and approved by the Faculty of dentistry Bani-suef university research Ethics committee (Approved number \#FDBSUREC/09062019/SA.The following patients were excluded; 1) individuals with systemic diseases related to bone resorption (e.g.; uncontrolled diabetics or osteoporosis), 2) Patients who had head and neck chemotherapy or radiation therapy, 3) Patient with harmful habits as smoking, clenching and bruxism, and 4) Uncooperative participants. All patients were informed about treatment line, then a written consent was signed by all patients. The study protocol was planned and done according to the ethical principles stated in Helsinki Declaration (https://www. wma.net).

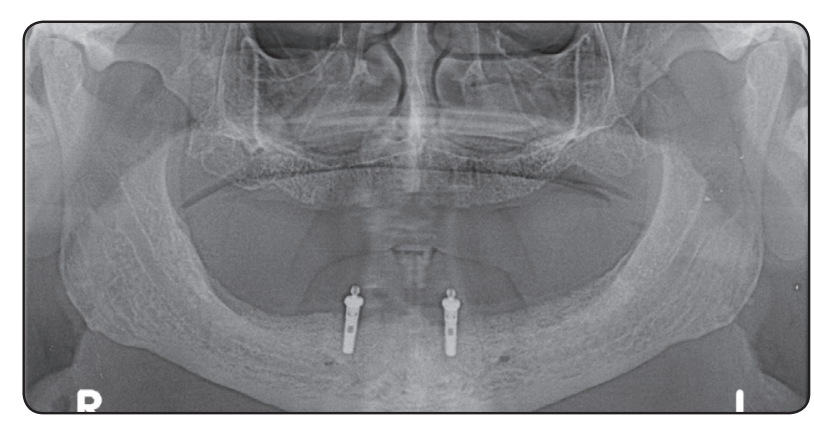

Fig. (1) Selected patients' criteria

A clear acrylic duplicate of the existing maxillary denture with metal radio-opaque markers at anticipated implant sites was constructed and used as a radiographic template. Preoperative examination of implant sites was performed using panoramic radiographs to determine the relation to maxillary sinuses. The radiographic template was then converted to a surgical template by attaching metal tubes at proposed implant sites. Mid crestal incision was made and full thickness mucoperiosteal flap was raised. Each participant received 4 implants (Tiologic ${ }^{\circledR}$ Implants, Dentaurum, Ispringen, Germany) in the maxillary arch between the maxillary sinuses (at canine and $2^{\text {nd }}$ premolar areas) using standardized 2- stage submerged surgical approach. the flap was closed with interrupted sutures. Three weeks postoperatively, the patient's existing maxillary dentures were relieved over implant sites and refitted to the mucosa using a tissue conditioner. Pos operative medications include: Antibiotics (amoxicillin and clavulanic acid (Augmentin 1gm/ twice dialy) continued for 10 days postoperatively, Nonsteroidal antiinflammatory drugs, analgesics, and mouth wash rinsing (chlorhexidine digluconate $0.2 \%$ ) continued daily for 7 days postoperatively.

After 6 months of osseointegration, implants were exposed and healing abutments were placed. The participants were randomly assigned into 2 groups using random numbers generated in Excel spread sheet. Group 1: included 5 participants who received locator retained maxillary overdentures (fig 2). Group 2; included 5 participants who received bar retained maxillary overdentures (fig 3 ). Allocation of participants was made to ensure equal gender distribution in each group to avoid the effect of hormonal disorders in females and the possibility of applying more occlusal force in males on the measured outcomes.

Two weeks later open tray impression procedure was started. Maxillary preliminary impression was made with irreversible hydrocolloid material (CA 37, Cavex Holland BV, Haarlem, Netherlands) and poured to obtain a diagnostic cast on which custom trays were fabricated with an open area in the implant region using autopolymerizing acrylic resin. Impression transfer copings with long screws were threaded into the implants and splinted with Duralay acrylic resin ${ }^{24}$. After border molding of the trays, light-body rubber base material was injected around the impression copings and the impression of the ridge was completed with medium body material (Impregum, Impregum Soft; 3M Deutschland $\mathrm{GmbH})$. The implant analogues were attached to the transfer and the final impressions were poured with stone (ZETA, Orthodontic Stone; WhipMix. Corp, Louisville, Ky). 


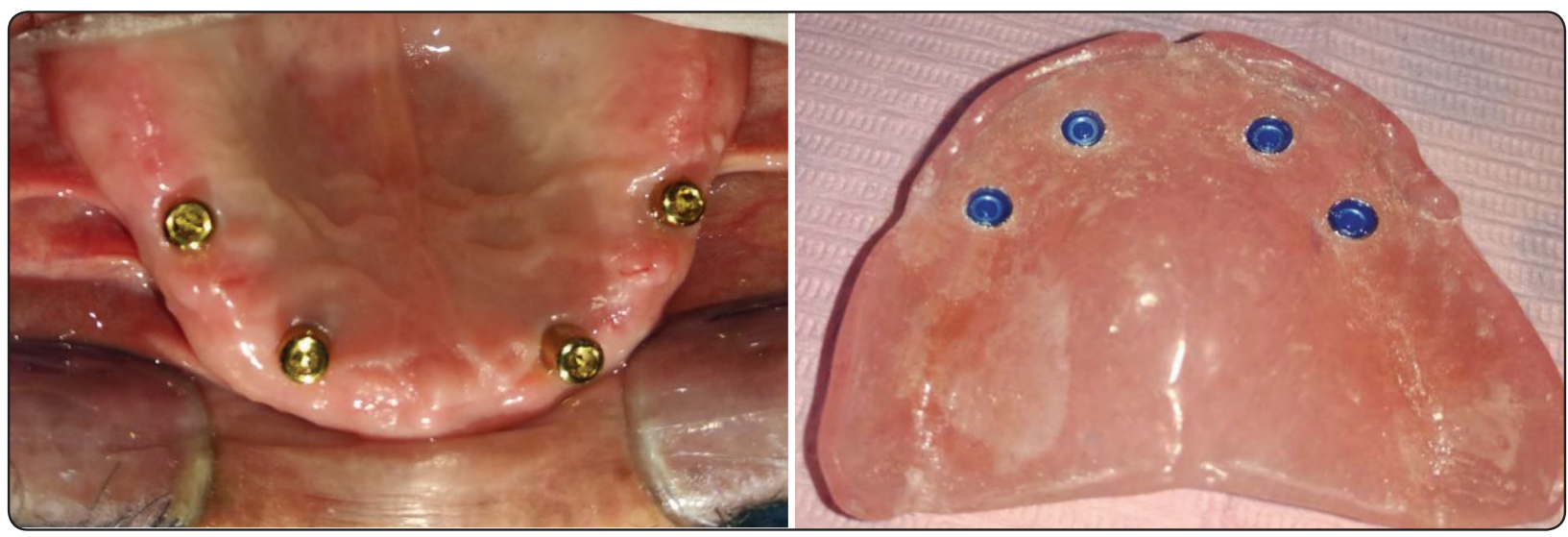

Fig. (2) Locator retained maxillary overdentures; a; in patient mouth, b, attachments in the fitting surface of the overdentures

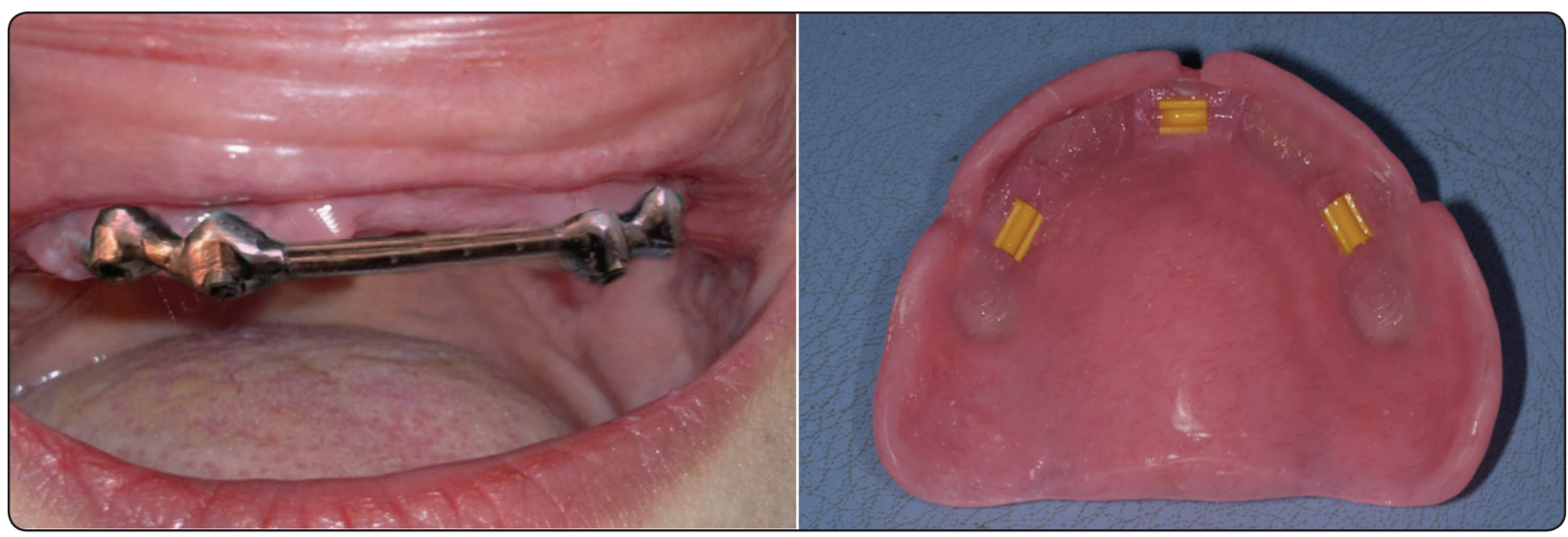

Fig. (3) Bar retained maxillary overdentures; a; in patient mouth, b, attachments in the fitting surface of the overdentures

In group 1, Locator abutments were screwed into the implant analogues and the locator metal housings (Tiologic ${ }^{\circledR}$ Implants, Dentaurum, Ispringen, Germany) with black processing insert were placed into each locator abutment on the model. In group 2, bar abutments (Tiologic $\AA$ Implants, Dentaurum, Ispringen, Germany) were screwed into the implant analogues and the implants were connected with a resilient bar (OT bar multiuse ${ }^{\circledR}$, RHEIN 83, Italy) leaving $2 \mathrm{~mm}$ clearance space between the bar and the ridge. Plastic pattern of the bar was luted to the plastic bar abutments with sticky wax and the assembly was sprued, invested, casted into cobalt-chromium alloy. The bar was tried in for passivity in patient mouth using single screw test. A new maxillary complete denture was constructed to occlude with existing mandibular ball retained overdentures. Record blocks were fabricated and jaw relations were recorded. Semi-anatomic teeth (Vitapan®,Vita Zahnfabrik, Bad Säckingen, Germany) were used and the functional masticatory concept was a bilateral balanced occlusion. On the models, metal housings for locators and bar clips were fastened to locator abutments and bar (between the implants) respectively. Maxillary dentures were processed in usual manner. For locator overdentures, the black processing inserts were replaced by blue nylon male inserts (light retention, Tiologic, Dentaurum, Germany). For bar overdentures, plastic retentive clips (Yellow, Medium retention, RHEIN 83. Italy) were placed in their metal housings. The new maxillary dentures 
were delivered to the patients with emphasis on oral hygiene instructions and 3-months regular recall visits for adjustments (of occlusion and borders) were scheduled all over the study period

\section{Implant related outcomes}

\section{A. Clinical outcomes}

The plaque index was assessed according to Modified plaque index ${ }^{25}$ scores by using a plastic periodontal probe run along the marginal area around each implant. The modified plaque index scores are; Score (0); no plaque was detected, Score (1); Plaque recognized only by running a probe across marginal surface area of the implant, Score (2); plaque was identified by naked eye, Score (3); abundance of soft material. The bleeding index was assessed according to Modified bleeding index ${ }^{25}$ scores. Score (0); no bleeding when periodontal probe was passed along the gingival margin, Score (1); isolated bleeding spots, Score (2); confluent red line of bleeding on gingival margin, Score (3); heavy or perfuse bleeding. The pocket depth was considered to be the distance between marginal gingiva and the tip of the probe in millimeters. This was measured by calibrated plastic periodontal probe. plaque and gingival indices, and probing depths were recorded at mid-mesial, mid-labial, mid-distal and mid lingual aspects of each implant. Implant stability was measured by means of resonance frequency analysis (RFA, Osstell ${ }^{\mathrm{TM}}$; Osstell AB, Gothenburg,
Sweden) and expressed with ISQ measurement scale (implant stability quotient) after attaching the implant-specific SmartPegs to the implant ${ }^{26,27}$

\section{B. Radiographic outcomes}

Cone beam computerized tomography (i-CAT device; Imaging Sciences Intl) was made at base line, 6 months $(6 \mathrm{~m})$, and 12 months $(12 \mathrm{~m})$ after maxillary denture delivery. The acquired DICOMs files were stored on a compact disc. The marginal bone resorption was measured at mesial, distal, buccal and lingual surface of each implant. Using a curve tool of the software (OnDemand3DApp Software; CyberMed Inc), a curve was drawn to bisect each implant from the occlusal (axial) view. The images were reconstructed by the software to give cross sectional image for each implant and panoramic images for all implants. Mesial and distal peri-implant bone resorption was measured at the panoramic images (fig 4). Buccal and lingual bone resorption was calculated at cross sectional images (fig5). To calculate marginal bone resorption, the vertical distance from implant abutment junction (point A) to the bone contact with implant (point B) was measured to give bone level ${ }^{28}$. Bone loss was calculated by subtracting bone levels at $6 \mathrm{~m}$ and $12 \mathrm{~m}$ from bone levels at base line. The bone loss measurement at all implants surfaces (mesial, distal, buccal and lingual) were averaged and the mean was subjected to statistical analysis.

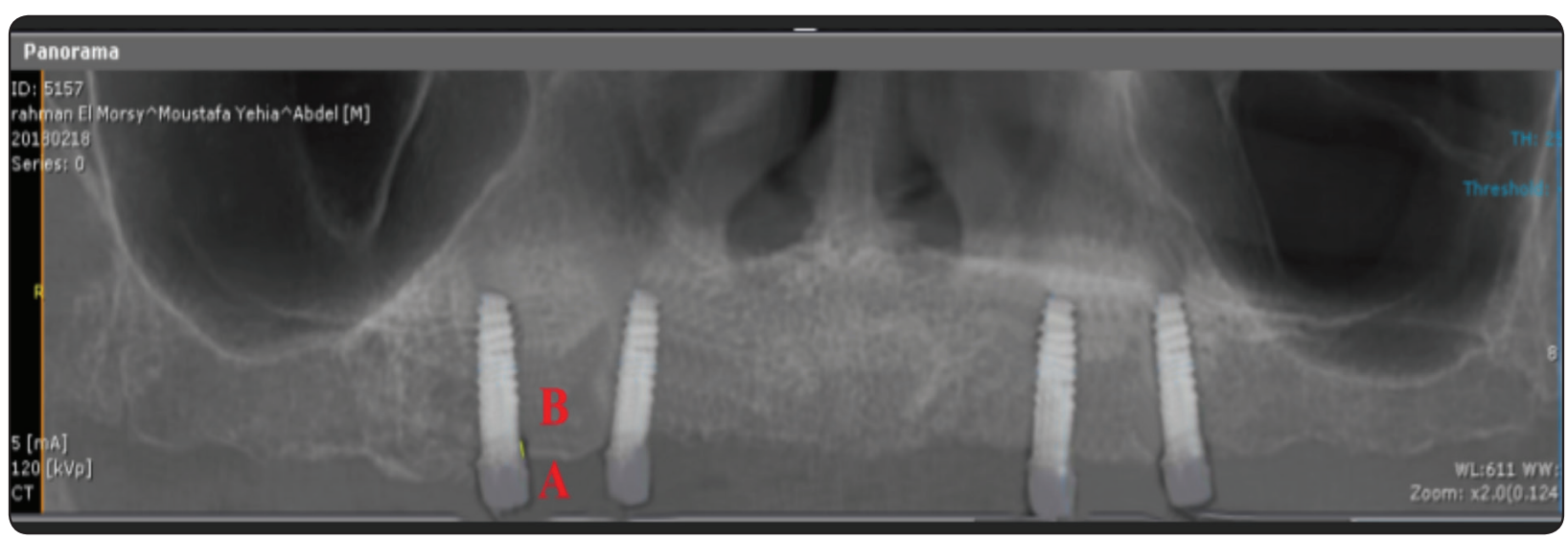

Fig. (4) Measurement of mesial and distal marginal bone loss in the panoramic images 


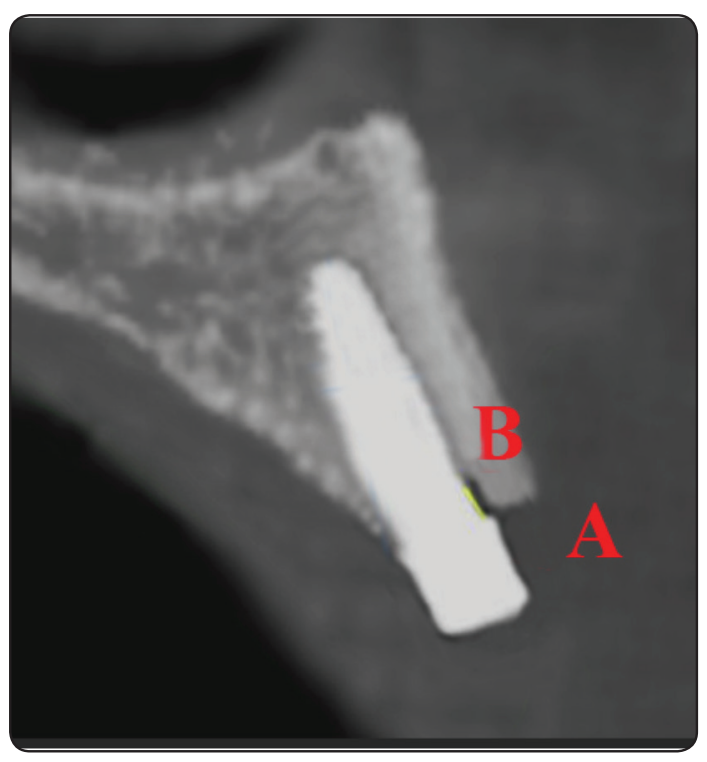

Fig. (5) Measurement of buccal and lingual marginal bone loss in the cross-sectional images

\section{Statistical analysis}

The data were non-parametric and violate the normal distribution. Freidman test was used to compare measured outcomes between observation times followed by Wilcoxon signed ranks test for pair wise comparisons between each 2 times. Mann Whitney test was used to compare the measured outcomes between the 2 groups. Mann Whitney test was also used to compare marginal bone loss between canine and premolar implants. The Data was analyzed by a computer program (SPSS v25.0; SPSS Inc). The level of significance was adjusted at $5 \%$.

\section{RESULTS}

Intention to treat analysis was followed. Two implants failed in 2 patients (one belonged to locator group, and one in bar group). Implant failures occurred during the healing period due to failure of osseointegration. Implant failures were associated with mobility and suppuration. The failed implants were removed and the patients were excluded from the study. All patients reported a marked improvement in retention and stability of their maxillary dentures as well as chewing ability.

Comparison of plaque index, gingival scores, probing depth, implant stability, and marginal bone resorption between groups and time intervals were presented in table 1. Plaque and gingival indices increased significantly with advance of time in bar group only while locator group demonstrated insignificant difference in plaque and gingival scores between observation times. Multiple comparisons between observation times showed significant difference in plaque and gingival scores between $\mathrm{T} 0$ and $\mathrm{T} 6$ and between $\mathrm{T} 0$ and $\mathrm{T} 12$ and between T6 and T12 (table 1). Bar overdentures recorded significant higher plaque and gingival scores than locator overdentures after 6 months and 12 months. No significant difference in pocket depth and implant stability was noted between time intervals or between groups

There was a significant difference in total marginal bone loss (average bone loss around mesial, distal buccal and lingual surfaces of canine and premolar implants) between time intervals and between groups. The total bone resorption increased significantly after 12 months compared to six months for both groups. Total marginal bone loss for locator group was significantly higher than bar group after 6 and 12 months. Comparison of total marginal bone loss between canine and premolar implants after 6 and 12 months were presented in fig 6 and fig 7 respectively. For both locator and bar groups, marginal bone loss around canine implants was significantly higher than bone loss around premolar implants (Mann Whitney test, $\mathrm{p}<.05$ ) 
TABLE (1) Comparison of measured outcomes between groups and observation times

\begin{tabular}{|c|c|c|c|c|}
\hline & Base line & 6 months & 12 months & Freidman test ( $\mathrm{p}$ value) \\
\hline \multicolumn{4}{|c|}{ Plaque index } & \\
\hline $\begin{array}{l}\text { Locator group } \\
\text { M (min-max) }\end{array}$ & $.6(.00-1.0) \mathrm{a}$ & $.6(.00-1.0) \mathrm{a}$ & $1.1(.00-2.0) \mathrm{a}$ & .36 \\
\hline $\begin{array}{l}\text { Bar group } \\
M(\min -\max )\end{array}$ & $.5(.00-1.0) \mathrm{a}$ & $1.63(1.0-2.0) \mathrm{b}$ & $2.0(1.0-3.0) \mathrm{c}$ & $.006^{*}$ \\
\hline Mann-Whitney test ( $\mathrm{p}$ value) & 1.00 & $.045^{*}$ & $.026 *$ & \\
\hline \multicolumn{5}{|c|}{ Gingival index } \\
\hline $\begin{array}{l}\text { Locator group } \\
\text { M (min-max) }\end{array}$ & $.1(.00-1.0) \mathrm{a}$ & $.44(.00-1.0) \mathrm{a}$ & $.64(.00-1.0) \mathrm{a}$ & .65 \\
\hline $\begin{array}{l}\text { Bar group } \\
\text { M (min-max) }\end{array}$ & $.43(.00-1.0) \mathrm{a}$ & $1.1(.00-2.0) \mathrm{b}$ & $1.5(.00-3.0) \mathrm{c}$ & $.037 *$ \\
\hline Mann-Whitney test ( $\mathrm{p}$ value) & .35 & $.042 *$ & $.012 *$ & \\
\hline \multicolumn{5}{|c|}{ Probing depth } \\
\hline $\begin{array}{l}\text { Locator group } \\
\text { M (min-max) }\end{array}$ & $1.8 \pm .60 \mathrm{a}$ & $2.0 \pm 1.0 \mathrm{a}$ & $2.3 \pm 1.3 \mathrm{a}$ & .095 \\
\hline $\begin{array}{c}\text { Bar group } \\
\text { M (min-max) }\end{array}$ & $1.5 \pm .70 \mathrm{a}$ & $2.0 \pm 1.2 \mathrm{a}$ & $2.5 \pm 1.4 \mathrm{a}$ & .078 \\
\hline Mann-Whitney test ( $\mathrm{p}$ value) & .13 & .69 & .13 & \\
\hline \multicolumn{5}{|c|}{ Implant stability } \\
\hline $\begin{array}{l}\text { Locator group } \\
\text { M (min-max) }\end{array}$ & $63.3 \pm 1.3 \mathrm{a}$ & $64.8 \pm 2.0 \mathrm{a}$ & $64.4 \pm 1.5 \mathrm{a}$ & .18 \\
\hline $\begin{array}{c}\text { Bar group } \\
\text { M (min-max) }\end{array}$ & $64.5 \pm 1.7 \mathrm{a}$ & $65.9 \pm 2.5 \mathrm{a}$ & $65.7 \pm 1.8 \mathrm{a}$ & .27 \\
\hline Mann-Whitney test ( $\mathrm{p}$ value) & .28 & .35 & .54 & \\
\hline \multicolumn{5}{|c|}{ Total marginal bone loss } \\
\hline $\begin{array}{l}\text { Locator group } \\
\text { M (min-max) }\end{array}$ & - & $1.81 \pm .64 \mathrm{a}$ & $2.06 \pm .47 \mathrm{~b}$ & $<.001 *$ \\
\hline $\begin{array}{c}\text { Bar group } \\
\text { M (min-max) }\end{array}$ & - & $1.26 \pm .48 \mathrm{a}$ & $1.41 \pm .54 \mathrm{~b}$ & $<.001^{*}$ \\
\hline Mann-Whitney test ( $\mathrm{p}$ value) & - & $<.020^{*}$ & $<.001^{*}$ & \\
\hline
\end{tabular}

M: median, min: minimum, max: maximum, $X:$ mean, SD: st deviation. Different letters in the same raw indicated a significant difference between each 2 time intervals (Wilcoxon signed ranks test, $p<.05$ ), and same letters indicate no significant difference *: p value significant at .05 


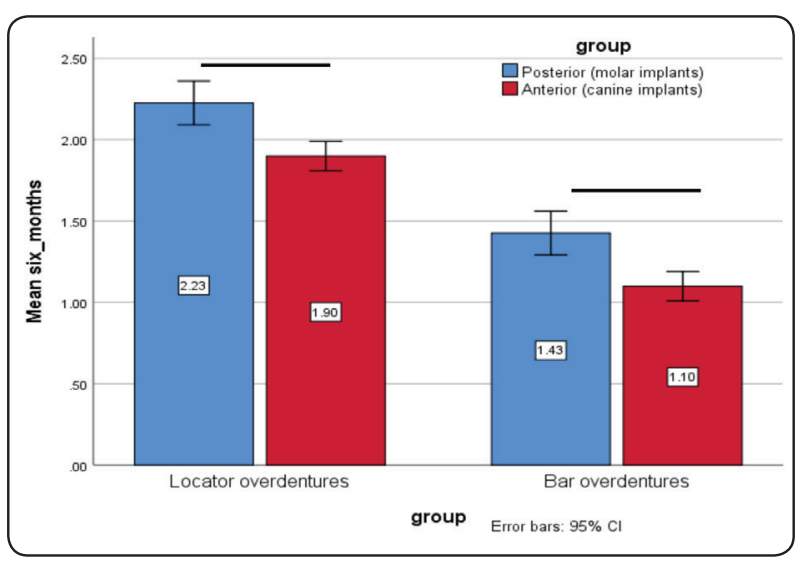

Fig. (6) Comparison of marginal bone loss between canine and premolar implants for both groups after 6 months. Line connecting columns indicate significant difference between canine and premolar implants

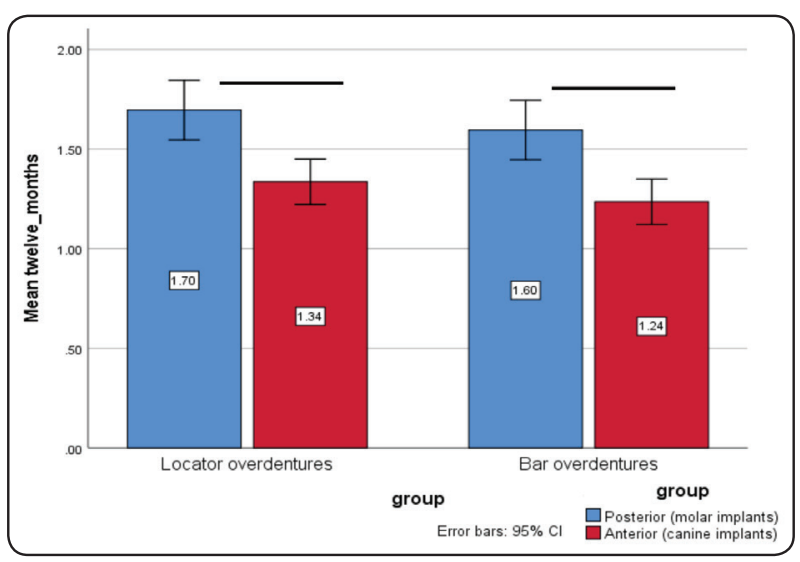

Fig. (7) Comparison of marginal bone loss between canine and premolar implants for both groups after 12 months. Line connecting columns indicate significant difference between canine and premolar implants

\section{DISCUSSION}

In the current investigation Cone bear computerized tomography (CBCT) was used for evaluation of marginal bone resorption as it provides information on bone loss on buccal and lingual aspects of the implants as well as mesial and distal aspects due to its three-dimensional nature. In contrast, Periapical radiography are 2 dimensional only. Moreover, CBCT, can be used easily especially with inclined palatine vault of the mouth without causing patient discomfort or gagging reflex as periapical radiographs do. CBCT also has no magnification or distortion as panoramic radiographs ${ }^{29,30}$. The use of CBCT in measuring bone resorption around implants was recommended by other investigators ${ }^{28,31}$. However, the disadvantages of CBCT are increased dose than conventional radiography and metal artefacts although it has minimal effect on measurements. ${ }^{32}$

Plaque and gingival indices increased significantly with advance of time in bar group. Also, bar overdentures recorded significant higher plaque and gingival scores than locator overdentures. The increased plaque accumulation under bars may be due to the difficulty of performing adequate oral hygiene by the patients investigated in this study and also may be related to spaces created within the denture base around the bar and the abutments that provide sheltered area for plaque to accumulate ${ }^{33}$. On the other, Locator attachments are more hygienic and self-cleansing ${ }^{21}$. A similar finding was observed in another study comparing the effect of bars and locators attachments for mandibular overdentures on soft tissue conditions ${ }^{34}$. The authors reported that hygienic maintenance is more complicated around bars when compared with unsplinted locator abutments. In line with our finding, Park et al. ${ }^{35}$ reported that plaque index, gingival index and bleeding on probing were significantly higher in the bar group than ball group for maxillary overdentures and concluded that bar attachments were more vulnerable than the ball attachments with respect to maintaining peri-implant tissue health. The reduced plaque and bleeding scores with locators are in line with another study in which the authors reported reduced scores of plaque and bleeding indices with locator retained maxillary overdentures. This may be attributed to the unsplinted nature and the smooth surface of the locator attachments which facilitate cleaning and oral hygiene procedures by the patients.

Although implant pocket depth increased with time, this increase was not significant. Also, no significant difference in pocket depth between 
groups was observed. The increased pocket depth may be due to increased bone loss. However, the lack of significant difference between observation times and groups could be attributed to the gingival recession around the implants that may occurred later. Implant stability did not differ also between observation times and between groups. This may be attributed to the reduced bone quality of maxillary bone. In line with this finding, Naert, et al. ${ }^{36}$ found no significant difference in implant stability between splinted and free-standing implants.

The largest amount of bone resorption was detected for locator attachments after 12 months (2.06 \pm .47). Also in another study, Wang et al. ${ }^{37}$ found that marginal bone loss around implants retain maxillary overdentures with locator attachments was high $(1.7 \pm 1.1 \mathrm{~mm})$. These values are higher than normal limit of marginal bone resorption reported in the literature which equal $1.2 \mathrm{~mm}$ during the first year $^{38,39}$. This increased bone loss necessities long term evaluation of bone resorption with locator retained maxillary overdentures opposed by implant retained mandibular overdentures to detect if bone loss will continue in a high or reduced rate. The total bone resorption increased significantly after 12 months compared to six months for both groups. In line with this observation, Elsyad et al. ${ }^{40,41}$ found increased vertical bone loss after one year compared to values at 6 months and justified the increased bone resorption to the bone response to prosthesis loading and bone reorganization combined with function stresses.

Total marginal bone loss for locator group was significantly higher than bar group after 6 and 12 months. A similar observation was noted in a recent study ${ }^{22}$ in which the authors compared marginal bone loss of maxillary implant overdentures retained bars or locator attachments and found than bone loss of locator group was higher than bar group after one year follow up period. This may be due to stress levels in surrounding bone tissues are significantly higher for four-implant maxillary overdentures with a solitary attachment system compared to a bar system ${ }^{42}$. The splinting of the implants by bars provide greater surface area and prevent implant micromotions ${ }^{43}$. The clips transmit the load indirectly to the implants through the bar while the unsplinted locators transmit to the implants directly. These forces are aggravated by implant disparallelism existed in the anterior region of the maxilla due to inclination of the alveolar bone of premaxilla. Therefore, implants are usually inclined labially. The implant inclination is not a problem with bar attachments. In contrast with locators, the external and internal flanges of the nylon components behave like guiding planes which restrict lateral movement of the prosthesis and may transmit moment loads to the implants during denture insertion and removal ${ }^{44-46}$. Another explanation may be due to Locator attachments were associated with high retention and stability after wear simulation with minimal retention loss compared to bar attachments for maxillary implant overdentures ${ }^{47}$. The increased retention of locator attachments may transfer increased stresses to the implants and thereby contribute to increased bone loss.

For both locator and bar groups in this study, marginal bone loss around canine implants was significantly higher than bone loss around premolar implants. This could be attributed to the increased masticatory load on the canine implants compared to premolar ones. It is widely accepted that interforaminal implants supporting mandibular overdentures creates a biomechanical situation similar to that of natural anterior teeth complicated with Combination syndrome ${ }^{4,5}$. Therefore, progressive tilting and settling of the mandibular overdenture under masticatory forces occurs. The high retention and stability of mandibular overdentures obtained with ball attachments improve masticatory function and increase bite forces. Therefore, the patients posture their mandibles forward to take advantage of the occlusal forces generated ${ }^{3}$. This will transmit high occlusal forces to the anterior (canine implants) compared to premolar implants ${ }^{48}$. 
The limitations of the study included the small sample size, the short evaluation period, the lack of evaluation of measurement of patient satisfaction with the 2 tested attachments. Therefore, long term randomized trials with sufficient sample size are still needed.

\section{CONCLUSION}

Within the limits of this study, it could be concluded that both locator and bar retained maxillary overdentures are successful treatment options for patients complaining from instability of maxillary dentures opposed by implant retained mandibular denture. However, locator attachments are advantageous in terms of peri-implant soft tissue health and bar attachments are advantageous regarding periimplant alveolar bone preservation.

\section{REFERENCES}

1. Kelly E. Changes caused by a mandibular removable partial denture opposing a maxillary complete denture. J Prosthet Dent. 1972;27:140-50.

2. Elsyad MA, Ashmawy TM, Faramawy AG. The influence of resilient liner and clip attachments for bar-implantretained mandibular overdentures on opposing maxillary ridge. A 5-year randomised clinical trial. J Oral Rehabil. 2014;41:69-77.

3. Elsyad MA, Khairallah AS, Shawky AF. Changes in the edentulous maxilla with ball and telescopic attachments of implant-retained mandibular overdentures: A 4-year retrospective study. Quintessence Int. 2013;44:487-95.

4. Maxson BB, Powers MP, Scott RF. Prosthodontic considerations for the transmandibular implant. J Prosthet Dent. 1990;63:554-8.

5. Thiel CP, Evans DB, Burnett RR. Combination syndrome associated with a mandibular implant-supported overdenture: a clinical report. J Prosthet Dent. 1996;75:107-13.

6. Saunders TR, Gillis RE, Jr., Desjardins RP. The maxillary complete denture opposing the mandibular bilateral distalextension partial denture: treatment considerations. J Prosthet Dent. 1979;41:124-8.

7. Tolstunov L. Combination syndrome: classification and case report. J Oral Implantol. 2007;33:139-51.
8. Sadowsky SJ. Treatment considerations for maxillary implant overdentures: a systematic review. J Prosthet Dent. 2007;97:340-8.

9. Naert I, Gizani S, van Steenberghe D. Rigidly splinted implants in the resorbed maxilla to retain a hinging overdenture: a series of clinical reports for up to 4 years. J Prosthet Dent. 1998;79:156-64.

10. Chan MF, Narhi TO, de Baat C, Kalk W. Treatment of the atrophic edentulous maxilla with implant-supported overdentures: a review of the literature. Int J Prosthodont. 1998;11:7-15.

11. Hutton JE, Heath MR, Chai JY, Harnett J, Jemt T, Johns $\mathrm{RB}$, et al. Factors related to success and failure rates at 3-year follow-up in a multicenter study of overdentures supported by Branemark implants. Int J Oral Maxillofac Implants. 1995;10:33-42.

12. Carlson B, Carlsson GE. Prosthodontic complications in osseointegrated dental implant treatment. Int J Oral Maxillofac Implants. 1994;9:90-4.

13. Akca K, Akkocaoglu M, Comert A, Tekdemir I, Cehreli MC. Human ex vivo bone tissue strains around immediately loaded implants supporting maxillary overdentures. Clin Oral Implants Res. 2005;16:715-22.

14. Carpentieri JR. Clinical protocol for an overdenture bar prosthesis fabricated with CAD/CAM technology. Pract Proced Aesthet Dent. 2004;16:755-7.

15. Naert I, Gizani S, Vuylsteke M, Van Steenberghe D. A 5 -year prospective randomized clinical trial on the influence of splinted and unsplinted oral implants retaining a mandibular overdenture: prosthetic aspects and patient satisfaction. J Oral Rehabil. 1999;26:195-202.

16. Spiekermann H. Implantology. In: Rateitschak, K.H. \& Wolf, H.F., eds. Color Atlas of Dental Medicine. New York: Thieme Medical Publishers. 1995:164.

17. Trakas T, Michalakis K, Kang K, Hirayama H. Attachment systems for implant retained overdentures: a literature review. Implant Dent. 2006;15:24-34.

18. Chung KH, Chung CY, Cagna DR, Cronin RJ, Jr. Retention characteristics of attachment systems for implant overdentures. J Prosthodont. 2004;13:221-6.

19. ELsyad MA, Errabti HM, Mustafa AZ. Mandibular Denture Base Deformation with Locator and Ball Attachments of Implant-Retained Overdentures. J Prosthodont. 2016;25:656-64.

20. Nguyen CT, Masri R, Driscoll CF, Romberg E. The effect of denture cleansing solutions on the retention of 
pink Locator attachments: an in vitro study. J Prosthodont. 2010;19:226-30.

21. Kleis WK, Kammerer PW, Hartmann S, Al-Nawas B, Wagner W. A comparison of three different attachment systems for mandibular two-implant overdentures: oneyear report. Clin Implant Dent Relat Res. 2010;12:209-18.

22. Boven GC, Meijer HJA, Vissink A, Raghoebar GM. Maxillary implant overdentures retained by use of bars or locator attachments: 1-year findings from a randomized controlled trial. J Prosthodont Res. 2019.

23. Zou D, Wu Y, Huang W, Wang F, Wang S, Zhang Z, et al. A 3-year prospective clinical study of telescopic crown, bar, and locator attachments for removable four implantsupported maxillary overdentures. Int $\mathrm{J}$ Prosthodont. 2013;26:566-73.

24. Zarb GA, Jansson T. Prosthodontic procedures. In: Brånemark, P.I., Zarb, G.A., Albrektsson, T. eds. Tissue Integrated Prostheses - Osseointegration in Clinical Dentistry p 251-270. 1985; Quintessence Publishing Co. Inc. Chicago, United States of America.

25. Mombelli A, van Oosten MA, Schurch E, Jr., Land NP. The microbiota associated with successful or failing osseointegrated titanium implants. Oral Microbiol Immunol. 1987;2:145-51.

26. Meredith N, Alleyne D, Cawley P. Quantitative determination of the stability of the implant-tissue interface using resonance frequency analysis. Clin Oral Implants Res. 1996;7:261-7.

27. Glauser R, Sennerby L, Meredith N, Ree A, Lundgren A, Gottlow J, et al. Resonance frequency analysis of implants subjected to immediate or early functional occlusal loading. Successful vs. failing implants. Clin Oral Implants Res. 2004;15:428-34.

28. Elsyad MA, Khirallah AS. Circumferential bone loss around splinted and nonsplinted immediately loaded implants retaining mandibular overdentures: A randomized controlled clinical trial using cone beam computed tomography. J Prosthet Dent. 2016;116 741-8

29. Naitoh M, Hayashi H, Tsukamoto N, Ariji E. Labial bone assessment surrounding dental implant using cone-beam computed tomography: an in vitro study. Clin Oral Implants Res. 2012;23:970-4.

30. Raes F, Renckens L, Aps J, Cosyn J, De Bruyn H. Reliability of circumferential bone level assessment around single implants in healed ridges and extraction sockets using cone beam CT. Clin Implant Dent Relat Res. 2013;15:661-72.
31. Razavi T, Palmer RM, Davies J, Wilson R, Palmer PJ. Accuracy of measuring the cortical bone thickness adjacent to dental implants using cone beam computed tomography. Clin Oral Implants Res. 2010;21:718-25.

32. Shiratori LN, Marotti J, Yamanouchi J, Chilvarquer I, Contin I, Tortamano-Neto P. Measurement of buccal bone volume of dental implants by means of cone-beam computed tomography. Clin Oral Implants Res. 2012;23:797-804.

33. Lachmann S, Kimmerle-Muller E, Gehring K, Axmann D, Gomez-Roman G, Watzek G, et al. A comparison of implant-supported, bar- or ball-retained mandibular overdentures: a retrospective clinical, microbiologic, and immunologic study of 10 edentulous patients attending a recall visit. Int J Prosthodont. 2007;20:37-42.

34. Cordaro L, di Torresanto VM, Petricevic N, Jornet PR, Torsello F. Single unit attachments improve peri-implant soft tissue conditions in mandibular overdentures supported by four implants. Clin Oral Implants Res. 2013;24:536-42.

35. Park JH, Shin SW, Lee JY. Bar versus ball attachments for maxillary four-implant retained overdentures: A randomized controlled trial. Clin Oral Implants Res. 2019.

36. Naert I, Gizani S, Vuylsteke M, van Steenberghe D. A 5-year randomized clinical trial on the influence of splinted and unsplinted oral implants in the mandibular overdenture therapy. Part I: Peri-implant outcome. Clin Oral Implants Res. 1998;9:170-7.

37. Wang F, Monje A, Huang W, Zhang Z, Wang G, Wu Y. Maxillary Four Implant-retained Overdentures via Locator(R) Attachment: Intermediate-term Results from a Retrospective Study. Clin Implant Dent Relat Res. 2016;18:571-9.

38. Albrektsson T, Zarb G, Worthington P, Eriksson AR. The long-term efficacy of currently used dental implants: a review and proposed criteria of success. Int J Oral Maxillofac Implants. 1986;1:11-25.

39. Adell R, Lekholm U, Rockler B, Branemark PI. A 15-year study of osseointegrated implants in the treatment of the edentulous jaw. Int J Oral Surg. 1981;10:387-416.

40. Elsyad MA, Mahanna FF, Elshahat MA, Elshoukouki AH. Locators versus magnetic attachment effect on periimplant tissue health of immediate loaded two implants retaining a mandibular overdenture: a 1-year randomised trial. J Oral Rehabil. 2016;43:297-305.

41. Elsyad MA, Elsaih EA, Khairallah AS. Marginal bone resorption around immediate and delayed loaded implants supporting a locator-retained mandibular overdenture. A 1-year randomised controlled trial. J Oral Rehabil. 2014;41:608-18. 
42. Geramy A, Habibzadeh S. Stress Distribution in Splinted and Unsplinted Implant-Supported Maxillary Overdentures: A 3D Finite Element Analysis. Implant Dent. 2018; 27:56-62.

43. Krennmair G, Krainhofner M, Piehslinger E. Implantsupported mandibular overdentures retained with a milled bar: a retrospective study. Int J Oral Maxillofac Implants. 2007;22:987-94.

44. Elsyad MA, Abid KS, Elkhalek EA. Effect of Buccal Implant Inclination on Stresses Around Two-Implant-Retained Overdentures with Resilient Stud Attachments. Int J Oral Maxillofac Implants. 2017;32:e135-e42.

45. Elsyad MA, Eltowery SM, Gebreel AA. Peri-implant strain around mesially inclined two implants retaining mandibular overdentures with Locator attachments. J Oral Sci. 2017:(in press)

46. ELsyad MA, Setta FA, Khirallah AS. Strains around distally inclined implants retaining mandibular overdentures with Locator attachments. An in vitro study. J Adv Prosthodont. 2016;8 116-24.

47. ELsyad MA, Dayekh MA, Khalifa AK. Locator Versus Bar Attachment Effect on the Retention and Stability of Implant-Retained Maxillary Overdenture: An In Vitro Study. J Prosthodont. 2019;28:e627-e36.

48. Abd El-Dayem MA, Assad AS, Abdel-Ghany MM. The effect of different mandibular dentures on antagonistic maxillary ridge. Implant Dent. 2007;16:421-9. 